Meta

Journal des traducteurs

Translators' Journal

\title{
Levée de rideau sur la poésie canadienne : prix littéraires, traduction et canonisation, d'hier à aujourd'hui
}

\section{Myriam Legault-Beauregard}

Volume 60, numéro 2, août 2015

$60^{\mathrm{e}}$ anniversaire. Les horizons de la traduction : retour vers le futur $60^{\text {th }}$ Anniversary. Translation's Horizons: Back to the Future

60mo aniversario. Los horizontes de la traducción: regreso al futuro

URI : https://id.erudit.org/iderudit/1032904ar

DOI : https://doi.org/10.7202/1032904ar

Aller au sommaire du numéro

Éditeur(s)

Les Presses de l’Université de Montréal

ISSN

0026-0452 (imprimé)

1492-1421 (numérique)

Découvrir la revue

Citer ce document

Legault-Beauregard, M. (2015). Levée de rideau sur la poésie canadienne : prix littéraires, traduction et canonisation, d'hier à aujourd'hui. Meta, 60(2),

353-353. https://doi.org/10.7202/1032904ar d'utilisation que vous pouvez consulter en ligne. 


\title{
Levée de rideau sur la poésie canadienne: prix littéraires, traduction et canonisation, d'hier à aujourd'hui
}

\author{
Myriam Legault-Beauregard \\ Université du Québec en Outaouais, Gatineau, Canada \\ legm27@uqo.ca
}

Tout comme la traduction, les prix accordés par diverses institutions peuvent contribuer à la canonisation des œuvres littéraires. Gisèle Sapiro évoquait en 2010 le «pouvoir de consécration » de la première; Barbara Godard, quant à elle, a déjà qualifié les seconds d'«instances de légitimation». Or, si quelques chercheurs, dont Spencer (2012) et Pickford (2011), se sont intéressés à la traduction d'œuvres récompensées par de grands prix européens comme le Goncourt, le Man Booker et le Buchpreis, les relations entre ces deux phénomènes demeurent peu étudiées en contexte canadien. Il y a pourtant matière à réflexion. En 1968, Philip Stratford notait que seuls 13 des 142 livres couronnés par les Prix littéraires du Gouverneur général (GG) depuis leur fondation, en 1936, avaient été traduits (cinq de l'anglais au français et huit du français à l'anglais). On peut se demander si la situation a évolué depuis. À cet effet, une cueillette de données exhaustive s'impose.

Dans le cadre de ce colloque anniversaire, nous souhaitons faire le point sur les recueils de poésie de langue anglaise ayant remporté un GG entre 1955 et aujourd'hui. Plus précisément, nous chercherons à déterminer combien d'entre eux ont été traduits en français, puis nous mettrons au jour certaines tendances: par qui et à quel moment ces livres ont-ils été traduits? L'instauration des subventions à la traduction du Conseil des arts a-t-elle changé la donne? Quels rapprochements peut-on faire avec d'autres distinctions canadiennes plus récentes, comme le Griffin Poetry Prize? Cette démarche permettra de mieux comprendre les mécanismes de canonisation de nos littératures nationales et de faire émerger de nouvelles avenues à explorer pour les poètes, les traducteurs et, bien entendu, les traductologues.

Myriam Legault-Beauregard étudie à la maîtrise en études langagières de l'Université du Québec en Outaouais. Ses principaux champs d'intérêt sont la traduction de poésie et les mécanismes de consécration des œuvres. Elle a fait partie du comité d'organisation du Colloque étudiant «Langagiers, langagières, unissons nos voies!», tenu en mars 2015, où elle a présenté une recherche sur les prix littéraires. En 2014, elle a prononcé une communication sur la traduction de poésie québécoise au Mexique avec Madeleine Stratford au Congrès de l'Association canadienne de traductologie. Elle a publié dans la revue k1n sa traduction en français du poème «The Hum» de la poète britannique Rachael Boast, et sa candidature a été retenue pour une résidence au Centre international de traduction littéraire de Banff en 2015 